(C) Elsevier Scientific Publishing Company, Amsterdam - Printed in The Netherlands

\title{
ON THE REGIONAL VARIATION OF HEAT FLOW, GEOTHERMS, AND LITHOSPHERIC THICKNESS *
}

\author{
HENRY N. POLLACK and DAVID S. CHAPMAN ** \\ Department of Geology and Mineralogy, The University of Michigan, Ann Arbor, \\ Michigan (U.S.A.)
}

(Submitted October 1975; revised version accepted August 11, 1976)

\begin{abstract}
Pollack, H.N. and Chapman, D.S., 1977. On the regional variation of heat flow, geotherms, and lithospheric thickness. Tectonophysics, 38: 279-296.

Geotherm families in which surface heat flow is the principal independent variable have been constructed for continental and oceanic lithospheres. The continental model is characterized by geotherms in which surface heat flow is in equilibrium with heat flowing into the lithosphere at its base plus heat generated by radioactive decay within the lithosphere. The model accommodates the regional variation of the surface heat flow with proportional variations in the radioactivity of the surficial enriched zone and in the deeper heat flow. The proportionality is dictated by a new and general linear relationship between reduced heat flow and mean heat flow for a region $\left(q^{*} \cong 0.6 \bar{q}_{0}\right)$, which enables both $q^{*}$ and the mean heat production of the enriched zone to be estimated from knowledge of the mean surface heat flow of a province. The oceanic model is characterized by the transient cooling of a semi-infinite medium with an initial temperature gradient and some near-surface radiogenic heat production. The model yields a heat flow in satisfactory agreement with observations in the oldest ocean basins. The depth at which both the oceanic and continental geotherms reach $\sim 0.85$ of the melting temperature is shown to be a consistent estimator of the depth to the top of the low-velocity channel, or the thickness of the high-velocity lid overlying the channel. We identify the lid as synonymous with the lithosphere, and produce a global map of lithospheric thickness based on the regional variation of surface heat flow. The lithosphere is less than $100 \mathrm{~km}$ thick over most of the globe, but thickens appreciably and becomes more viscous beneath the Precambrian shields and platforms, regions of low heat flow. These characteristics of shields are consistent with recently reported models of the driving mechanisms of the plate sys tem, which require greater retarding forces beneath plates with large continental areas.
\end{abstract}

\section{INTRODUCTION}

The purpose of this paper is to utilize a representation of the global heatflow field to determine regional geotherms, and on the basis of these geo-

\footnotetext{
* Presented at the Symposium on Heat Flow and Geodynamic Processes, International Union of Geodesy and Geophysics, Grenoble, France, August, 1975.

** Present address: Department of Geology and Geophysics, The University of Utah, Salt Lake City, Utah, 84112, U.S.A.
} 
therms map variations in thermally controlled properties of the earth's upper mantle, in particular the thickness of the lithosphere.

The concept that the depth to important changes or transitions in physical properties within the earth is dependent on the regional heat flux and geotherm is not of recent origin; Kennedy (1959) speculated that the variable depth to the Moho (thought by him to be the gabbro-eclogite phase change) beneath oceans, continents, and mountain ranges was linked to variations in the heat flux and geotherms between these respective regions. At that time heat-flow measurements were insufficient in number and distribution to test this or any other hypothesis dependent on heat-flow data, but in the early 1960 's measurements of the geothermal flux, both on land and at sea, began to accumulate. By 1964 the rough equality of oceanic and continental heat flow had been recognized, as well as the fact that the flux through continental shields was well below the global mean. On the basis of these early observations, Clark and Ringwood (1964) developed petrological and thermal models of the outer 400 kilometers of the earth for three continental regions with heat flow of $1.0,1.2$, and $1.5 \mu \mathrm{cal} \mathrm{cm} \mathrm{cm}^{-2} \mathrm{sec}^{-1}\left(42,50\right.$ and $63 \mathrm{~mW} \mathrm{~m}^{-2}$, respectively) and for an oceanic region with heat flow of $1.2 \mu \mathrm{cal} \mathrm{cm}-2$ $\mathrm{sec}^{-1}$. These regional geotherms still receive wide usage in the petrological community (see for example, Boyd, 1973). In the decade since the Clark and Ringwood regional models, the recognition of the ocean floor as a cooling plate of lithosphere (McKenzie, 1967; Sclater and Francheteau, 1970), with diminishing heat flow and elevation away from the spreading ridge, has made necessary the abandonment of a steady-state oceanic geotherm closely tied to radiogenic heat-source distributions, except perhaps, for the oldest segments of the oceanic lithosphere. Consequently, time-dependent models with a characteristic heat flow and geotherm related to lithosphere of a particular age, have now replaced earlier equilibrium heat flux and geotherm models for the oceans.

On the continents, the concept of heat flow varying with tectonic province has been extended beyond the early recognition of low heat flow on shields. Polyak and Smirnov (1968) first delineated a clear progression of decreasing heat flow from younger to older tectonic provinces, providing a time scale for the decay of heat flux on the continents, extended over a time interval an order of magnitude greater than the oceanic decay.

In another paper (Chapman and Pollack, 1975b) we have utilized the present state of understanding of the relationship of heat flow to age of tectonic element to synthesize a global heat-flow field. We now use that heatflow field as the principal constraint in the construction of regional geotherms extending to depths of a few hundred kilometers. The temperature models are constructed so that specification of the surface heat flow fully determines a geotherm. This requires that many variables of the thermal models be reasonably fixed, and that some aspects, such as heat-source distributions, be parametrically related to the heat flow. Following the establishment of regional geotherms, we discuss the resulting spatial variation in the 
thermal field and in some temperature-dependent physical properties of the upper mantle. Special attention is given to the rheology of the outer few hundred kilometers, and the effect of temperature variations on the thickness of the lithosphere.

\section{THE GLOBAL HEAT FLUX}

The heat conducted to the surface of the earth from its interior averages about $60 \mathrm{~mW} \mathrm{~m}^{-2}$, and most of the regional variation in the heat flux lies within a factor of three about the mean. Measurements have been obtained in some 829 of the $25925^{\circ} \times 5^{\circ}$ latitude-longitude grid elements that make up the surface of the earth. These 829 elements amount to about $42 \%$ of the surface area.

In spite of this incomplete coverage, the present understanding of the regional distribution of heat flux makes it possible to use prediction methods together with existing tectonic and geologic information to estimate with considerable confidence mean heat flows for the remaining unsurveyed $5^{\circ} \times$ $5^{\circ}$ regions.

In Chapman and Pollack (1975b) we describe an empirical heat-flow predictor, which is used to supplement existing observations to create a full global heat-flow data set, and the degree-12 spherical harmonic analysis of the surface heat-flow field thereby obtained. The reconstruction (synthesis) of the degree-12 field is shown in Fig. 1. The most important characteristics of this representation are the excellent delineation of the features of the heat-flow field already established from measurements, and the absence of

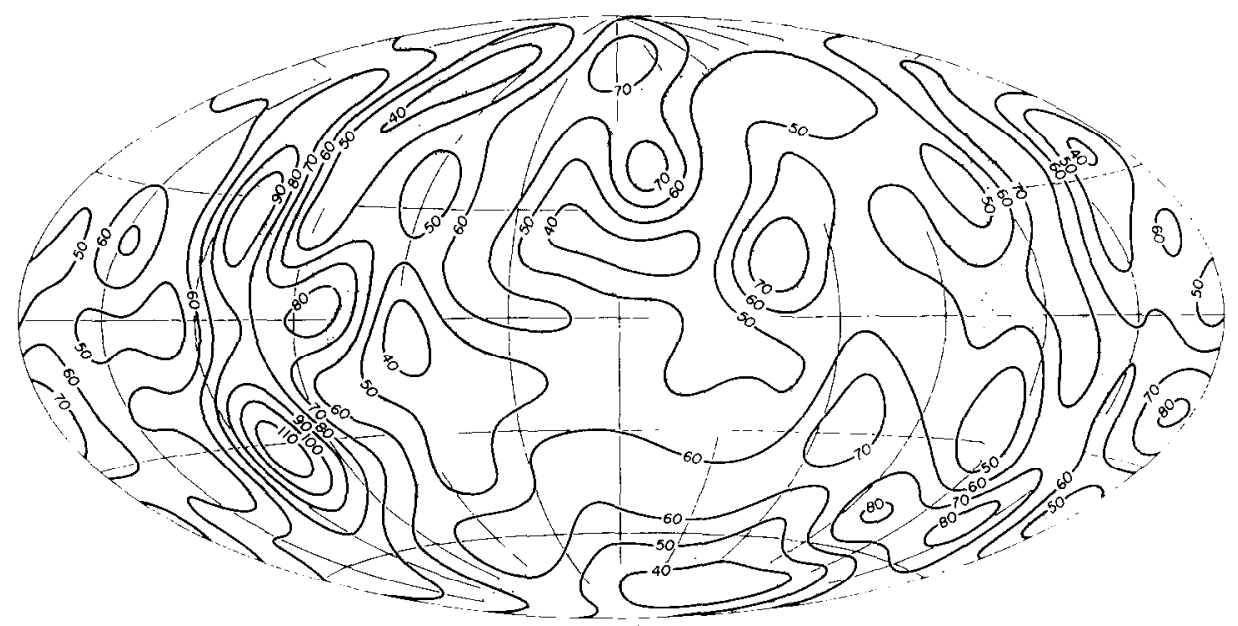

Fig. 1. Degree-12 spherical harmonic representation of global heat flow from observations supplemented by predictor. Heat flow in $\mathrm{mW} \mathrm{m}^{-2}$. 
unrealistic distortions in regions where no observations exist. All the major oceanic ridge systems are represented as heat-flow highs, as are the marginal basins of the West Pacific, Alpine Europe, and the American Cordillera. Low heat-flow regions include all the major shields and platforms, and the oldest oceanic regions.

Thus we believe that Fig. 1 is a realistic representation of the global heatflow field. In the following section we utilize this field as the principal constraint in the construction of crustal and upper-mantle geotherms.

\section{REGIONAL GEOTHERMS}

In the calculation of representative geotherms, we use conduction theory throughout, and extend the geotherms only to the base of the lithosphere, a depth which we believe seldom exceeds 300 kilometers and over most of the earth is much less. Continuation of the geotherms into the asthenosphere is likely to require a departure from purely conductive models of heat transfer. We consider separate computational models for continental and oceanic regions.

\section{Continents}

' For the continents the computational model we use is one of steady-state conduction, in which the surface heat flow is in equilibrium with the heat flowing into the lithosphere at its base plus the heat generated by radioactive decay within the lithosphere. The time required for the surface heat flow to be in equilibrium with internal heat sources uniformly distributed in a 100$\mathrm{km}$ slab is less than $300 \mathrm{~m} . \mathrm{y}$, and considering that most of the radiogenic flux arises in the outer 40 kilometers, the time to reach a steady state is probably less than $50 \mathrm{~m} . \mathrm{y}$. Furthermore, younger terrains $(<50 \mathrm{~m} . \mathrm{y}$. since last mobilization) are characterized by higher heat flow, a steeper geotherm, and thinner lithosphere, and as we will illustrate shortly, there is little difference between steady and transient geotherms, within the relatively thin lithospheric domain in high heat-flow regions.

The geotherm for a given continental region depends on the surface heat flow, the vertical distribution of heat production sources, and the variation of thermal conductivity with temperature (and hence depth). Adequate experimental data exist to provide guidance on the temperature dependence of conductivity. We have used $2.5 \mathrm{Wm}^{-1} \mathrm{~K}^{-1}$ throughout the crust, and a temperature dependence above $500^{\circ} \mathrm{C}$ following Schatz and Simmons (1972). In contrast, the vertical distribution of heat sources throughout the lithosphere is not known by direct measurement, and must be estimated from geological and petrological arguments. The heat production of nearsurface rocks has of course been measured in many locales, and the variation of surface heat flow within several heat-flow provinces has been observed to be a linear function of the heat production of the near-surface rocks. This 
relationship was first reported for plutonic rocks by Birch et al. (1968), and now seems to be quite applicable in many non-plutonic settings as well. The relationship is expressed by $q_{0}=q^{*}+b A_{0}$ where $q_{0}$ is the surface heat flow, $A_{0}$ is the heat production of the surface rocks, $q^{*}$ is the "reduced" heat flow (the heat flow intercept for zero heat production) and $b$ is a quantity with dimension of depth which characterizes the vertical source distribution. Several heat-production distributions satisfy the above relationship (Birch et al., 1968; Lachenbruch, 1970), although only the exponential source model of Lachenbruch maintains the relationship through differential erosion. The linear heat flow vs. heat production relationship offers a reasonable explanation, in terms of variations in shallow crustal radioactivity, for the range of heat flow within a heat flow province.

The variation of the parameters $q^{*}$ and $b$, between provinces has been less well studied. In what follows we will demonstrate a new and simple empirical relationship between $q^{*}$ and $\bar{q}_{0}$, the mean heat flow within a province, that enables an estimate of $q^{*}$ to be made from a knowledge of the mean heat flow of the province.

In Table I we have assembled much of the available data for heat-flow provinces for which reduced heat flow has been estimated. The entries in Table I are of varying quality, ranging from tightly constrained values where least-squares lines have been fitted to many heat-flow-heat-production pairs, to a few measurements with insufficient range for reliable estimates of $q *$ and $b$ by line fitting. In the latter situation $b$ was usually assumed and a line passing through the cluster of points was assumed. The estimates of $\vec{q}_{0}$, the mean heat flow of a province, are given by the original authors, or have been extracted from graphs or calculated from data lists by us.

Provided the heat-flow sites are representative of the province as a whole, one can show that $\bar{q}_{0}=q^{*}+b \bar{A}_{0}$ where $\bar{A}_{0}$ is the mean heat generation of the province. Thus the mean heat flow of a province, like the local flux at individual sites, comprises contributions from within and below an enriched zone.

It is apparent from Table I that $b$ lies within a quite restricted range; $8.5 \pm$ $1.5 \mathrm{~km}$ encompasses most results. The effect that a 3-kilometer range in $b$ can have on the variation of $\bar{q}_{0}$ between provinces can be easily estimated. Assume that $q^{*}$ and the mean heat production are the same for two provinces, but that $b$ differs by the above indicated range of 3 kilometers. For a typical upper-crustal heat production of $2.5 \mu \mathrm{W} \mathrm{m} \mathrm{m}^{-3}$ one would obtain a variation in $\bar{q}_{0}$ of only $7.5 \mathrm{~mW} \mathrm{~m}^{-2}$. As differences between provinces range up to several tens of $\mathrm{mW} \mathrm{m} \mathrm{m}^{-2}$, it is clear that the major element in the variation of mean heat flow from province to province must be variations in $\ddot{A}_{0}$ and $q^{*}$, the mean heat production within and the input from below the enriched surface zone, respectively.

We have plotted $q^{*}$ versus $\bar{q}_{0}$ (Fig. 2 ) for the regions and data shown in Table I. A linear relationship emerges from which we tentatively establish a new empiricism relating reduced heat flow to mean surface heat flow in a 
TABLE I

Mean heat flow, reduced heat flow, and characteristic depth of heat source distribution, for several heat flow provinces

\begin{tabular}{|c|c|c|c|c|}
\hline Province & 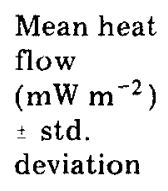 & $\begin{array}{l}\text { Reduced heat } \\
\text { flow } \\
\left.\text { ( } \mathrm{mW} \mathrm{m}^{-2}\right) \\
\pm \text { uncertainty }\end{array}$ & $\begin{array}{l}\text { Character- } \\
\text { istic depth } \\
b(\mathrm{~km})\end{array}$ & References \\
\hline Basin and Range & $92 \pm 13$ & $59 \pm 8$ & 9.4 & $\begin{array}{l}\text { Roy et al. }(1968) \text {; } \\
\text { Sass et al. }(1971) \\
\text { Sass and Munroe } \\
(1974)\end{array}$ \\
\hline Central Australia & $77 \pm 10$ & $27 \pm 6$ & 11.1 & Jaeger (1970) \\
\hline Zambia & $67 \pm 7$ & $40 \pm 6$ & & $\begin{array}{l}\text { Chapman and Pollack } \\
\text { (1975a) }\end{array}$ \\
\hline Eastern U.S.A. & $57 \pm 17$ & $33 \pm 4$ & 7.5 & Roy et al. (1968) \\
\hline Canadian shield & $39 \pm 7$ & $28 \pm 6$ & 9.8 & Rao and Jessop (1975) \\
\hline Western Australia & $39 \pm 8$ & $26 \pm 8$ & 4.5 & $\begin{array}{l}\text { Jaeger (1970); Rao } \\
\text { and Jessop (1975) }\end{array}$ \\
\hline Sierra Nevada & $39 \pm 12$ & $17 \pm 2$ & 10.1 & $\begin{array}{l}\text { Sass et al. (1971); Sass } \\
\text { and Munroe (1974) }\end{array}$ \\
\hline Baltic shield & $36 \pm 8$ & $22 \pm 6$ & 8.5 & Rao and Jessop (1975) \\
\hline Niger & $20 \pm 8$ & $11 \pm 8$ & 8 & $\begin{array}{l}\text { Chapman and Pollack } \\
(1974)\end{array}$ \\
\hline
\end{tabular}

heat-flow province:

$q^{*} \cong 0.6 \bar{q}_{0}$

Simply stated, within a continental region with mean heat flow $\bar{q}_{0}$, approximately 0.4 of the mean flux arises from near-surface radiogenic sources, and 0.6 comes from greater depths.

This empirical partition of $\bar{q}_{0}$ thus fixes the contribution of the enriched zone at $b \vec{A}_{0}=0.4 \bar{q}_{0}$ which, if $b$ is known or assumed, yields the mean heat production of the enriched zone. In our calculation of geotherms we have assumed $b=8 \mathrm{~km}$ uniformly.

Turning now to $q^{*}$, we believe that it is made up of a radiogenic contribution from the lower crust and upper mantle, and a deeper contribution which arises from radioactive decay and/or viscous dissipation in the asthenosphere, and which enters the lithosphere at its base. The heat production of the lower crust has been studied by several investigators (Hyndman et al., 1968; Smithson and Decker, 1974). While some uncertainty exists, principally due to uncertainty in the petrology of the deep crust, it is clear that the lower crust is substantially less endowed with heat-producing isotopes 


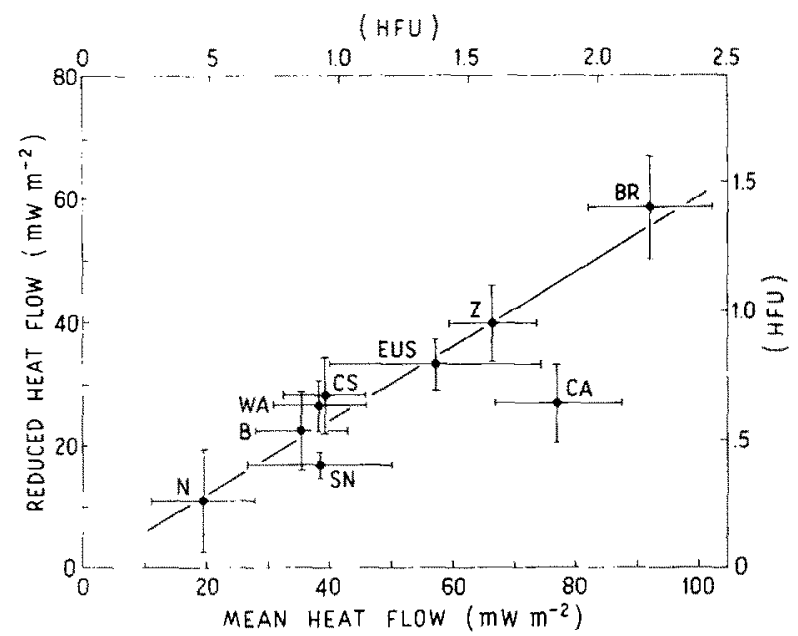

Fig. 2. Reduced heat flow versus mean heat flow in several heat-flow provinces. Horizontal bars represent standard deviation about the mean heat flow; vertical bars represent uncertainty of estimate of reduced heat flow. Regions represented: $\mathrm{N}=\mathrm{Niger}, \mathrm{B}=\mathrm{Baltic}$ shield, $\mathrm{SN}=$ Sierra Nevada, $\mathrm{WA}=$ western Australia, $\mathrm{CS}=$ Canadian shield, $\mathrm{EUS}=$ eastern United States, $\mathrm{Z}=\mathrm{Zambia}, \mathrm{CA}=$ central Australia, $\mathrm{BR}=$ Basin and Range.

than the surface enriched zone. What is totally unknown is whether the lower crustal endowment is directly or inversely proportional to the uppercrustal enriched zone, i.e. whether an increment of surface enrichment is accompanied by a proportional increment or decrement in the lower crust. The former would imply enrichment of the entire crust from the mantle, the latter would imply enrichment of the upper crust at the expense of the lower crust. Petrological arguments can be made for both situations. We judge the issue unresolved, and thus opt for a uniform lower-crustal heat production independent of the variation in upper-crustal enrichment implied in the $\bar{q}_{0}$ vs. $q^{*}$ relationship (Fig. 2). We have chosen $0.25 \mu \mathrm{W} \mathrm{m}^{-3}$ for the heat production of the lower crust, a value representative of intermediate-composition granulite-facies rocks.

Between the base of the crust and the base of the lithosphere we follow closely but not exactly the model of Sclater and Francheteau (1970) which has a depleted ultrabasic zone with a characteristic heat production of $10^{-2} \mu \mathrm{W} \mathrm{m}^{-3}$ overlying pyrolite with heat production $8.4 \cdot 10^{-2} \mu \mathrm{W} \mathrm{m} \mathrm{m}^{-3}$. We place the boundary between the two at $120 \mathrm{~km}$ depth. The depleted zone contributes less than $1 \mathrm{~mW} \mathrm{~m} \mathrm{~m}^{-2}$ to the surface flux; its effect on the curvature of the geotherm is minimal. The principal curvature in the geotherms is achieved below the depleted zone.

A family of geotherms can now be calculated, the family parameter being the surface heat flow. Figure 3 shows continental geotherms corresponding to various heat flows. The respective geotherms have been extended to depths at which they intersect a refractory mantle solidus, but have been 


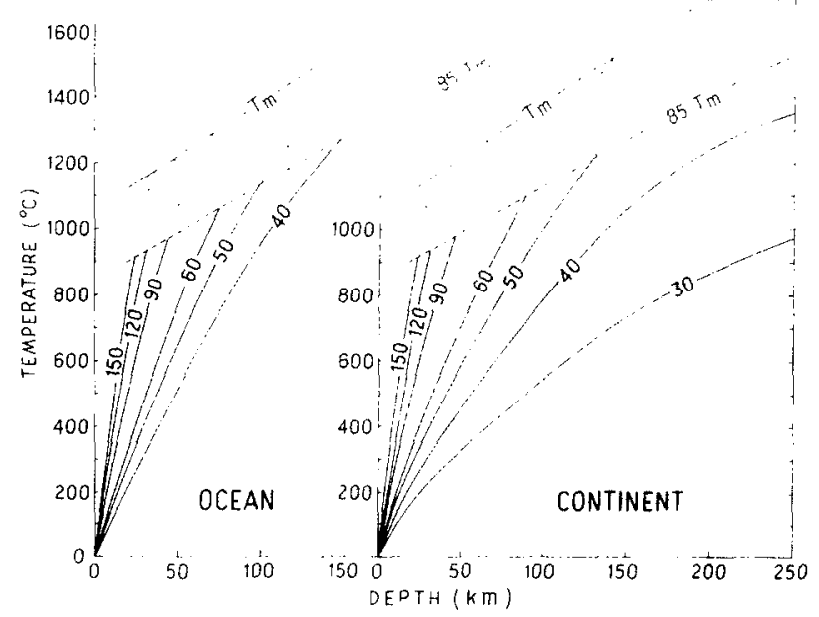

Fig. 3. Geotherm families for oceanic and continental regions; family parameter is heat flow in $\mathrm{mW} \mathrm{m}^{-2} . T_{\mathrm{m}}$ is mantle solidus; geotherms dotted above $0.85 T_{\mathrm{m}}$ to indicate provisionality.

dotted to indicate provisionality above 0.85 of the absolute solidus temperature. For reasons delineated in a later section, we believe that the lithosphere-asthenosphere transition may begin at a temperature less than the solidus, and we are hesitant to extend a purely conductive geotherm into the asthenosphere. The geotherms are all characterized by near-surface curvature due to the crustal heat production, a nearly linear gradient through the depleted zone, and for those geotherms not terminated by the solidus, a deeper region of curvature due in part to the enhanced thermal conductivity at higher temperatures and in part due to the heat production of the undifferentiated pyrolite. For heat flow below about $55 \mathrm{~mW} \mathrm{~m}^{-2}$ geotherms do not intersect the solidus; for flux below about $45 \mathrm{~mW} \mathrm{~m}^{-2}$ geotherms do not reach $0.85 T_{\mathrm{m}}$.

\section{Oceans}

The principal characteristic of the thermal regime of the oceanic lithosphere is its transient cooling following formation at a spreading ridge. In pioneering calculations, McKenzie (1967) and Sclater and Francheteau (1970) showed that the variations of heat flow and topography away from spreading ridge are reasonably explained by the cooling and contraction of a slab of uniform thickness and with isothermal lower boundary. Subsequent calculations by several workers (Parker and Oldenburg, 1973; Davis and Lister, 1974) have retained the fundamental concept of a cooling slab but have relaxed the constraint of uniform thickness. These models have in common a thermal definition for the base of the slab, i.e. the depth at which the 
actual temperature reaches some constant value, or some specified fraction of the solidus temperature.

The basis of our oceanic geotherms is the error-function solution for the one-dimensional cooling of a semi-infinite medium with an initial linear gradient, in which there is some radiogenic heat in the upper ten kilometers. Sclater et al. (1975) criticize the use of the simple error-function solution by Davis and Lister (1974) because it fails to yield heat flow adequate to match the observations in the older regions of the oceans, data which Sclater et al. (1975) believe are the only measurements that are quantitatively reliable. We surmount that valid criticism in part by including in the initial condition a linear gradient. Thus we allow the oceanic lithosphere to cool from an initial state of $T(z, 0)=T_{0}+c z$ where $T_{0}$ is $1300^{\circ} \mathrm{C}$ and $c$ is $1.5 \mathrm{~K} \mathrm{~km}^{-1}$. The gradient is somewhat less than the solidus gradient, such that the initial condition is sub-solidus below a depth of about $150 \mathrm{~km}$, i.e. the zone of partial melting at an oceanic ridge extends only to that depth. We have also included a $10-\mathrm{km}$ surface layer with a characteristic heat production of 0.5 $\mu \mathrm{W} \mathrm{m}{ }^{-3}$. The initial gradient and heat production together contribute a steady $10 \mathrm{~mW} \mathrm{~m} \mathrm{~m}^{-2}$, or almost a quarter of the heat flow in the old oceans. It is this extra increment to the error-function solution that enables the old ocean heat-flow constraint to be met. An average thermal conductivity of $3.35 \mathrm{~W} \mathrm{~m}^{-1} \mathrm{~K}^{-1}$ has been used throughout. The heat flow as a function of age from our model is shown in Fig. 4 ; it can be seen to yield $44 \mathrm{~mW} \mathrm{~m}^{-2}$ at $160 \mathrm{~m} . \mathrm{y}$., and does not fall below $40 \mathrm{~mW} \mathrm{~m}^{-2}$ until somewhat beyond 200 m.y.

A family of oceanic geotherms, with surface heat flow as the family parameter, is shown in Fig. 3. The parameter could also be indicated by age, via the heat-flow age relationship of Fig. 4. The oceanic geotherms intersect the solidus until the surface flux falls below about $65 \mathrm{~mW} \mathrm{~m}^{-2}$, or equivalently until the ocean reaches an age of about $70 \mathrm{~m} . \mathrm{y}$.

\section{Comparison of oceanic and continental geotherms}

The sets of geotherms in Fig. 3 reveal one remarkable aspect: while within both continents and oceans there is considerable variation between geotherms yielding different surface heat flows, for a given heat flow both continental and oceanic geotherms are remarkably similar. This is particularly true for geotherms yielding heat flow greater than $60 \mathrm{~mW} \mathrm{~m}^{-2}$. For lesser heat flow the respective continental and oceanic geotherms progressively diverge, separating by $230^{\circ}$ at $150 \mathrm{~km}$ depth for the $40 \mathrm{~mW} \mathrm{~m}^{-2}$ geotherms. It is this difference between continents and oceans in the low heat-flow regions that we later call upon to help explain the apparent greater resistance to lithospheric motion beneath shields. Lateral density gradients implicit in the regionally variable heat flow and geotherms are characteristically about $10^{-5}$ $\mathrm{g} \mathrm{cm}^{-3} \mathrm{~km}^{-1}$, and are unlikely to exceed twice that value. Thus lateral tem- 


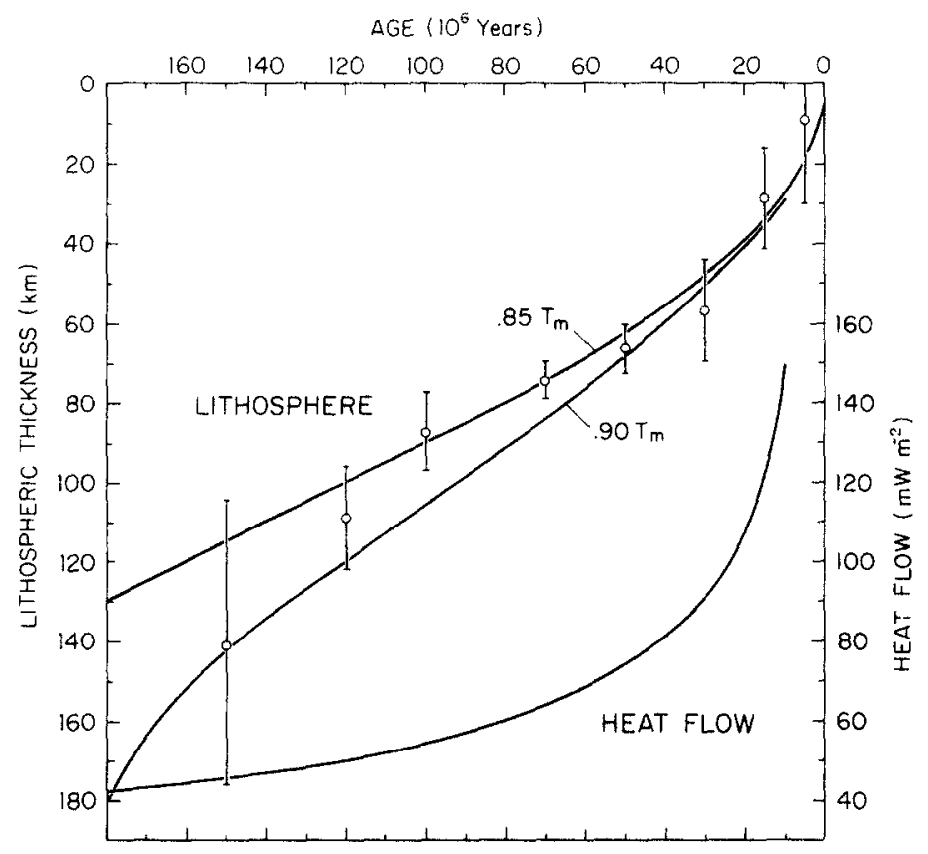

Fig. 4. Lithospheric thickness and heat flow versus age of ocean floor. Above: Data points with error bars represent estimates of lithospheric thickness from seismological data by Leeds et al. (1974); solid lines represent intersection of geotherms of Fig. 3 with 0.85 and $0.90 T_{\mathrm{m}}$. Below: Heat flow as function of age resulting from oceanic thermal model of this paper.

perature gradients in the lithosphere would appear to be inadequate to account for the observed undulations of the geoid.

\section{LITHOSPHERIC THICKNESS}

The physical properties of the crust and upper mantle, such as the seismic velocities and attenuation, the density, electrical conductivity, and viscosity are all more or less dependent on the ambient temperature and/or the ratio of the ambient temperature to the melting temperature (the mantle solidus). As we have already referred to the mantle solidus in the discussion of geotherms, and will return to it again, it is worthwhile here to digress briefly on the solidus.

We have assembled in Fig. 5 available experimental data and theoretical estimates of the mantle melting curve. The experimental curves show considerable variation, corresponding in part to the variety of materials and conditions used in the experiments. Solidus curves $A$ and $C$ represent natural lherzolites, $D$ for a natural peridotite, and $B$ for pyrolite, all under anhydrous conditions. Solidus curves $E$ and $H$ are lherzolite samples under partly 


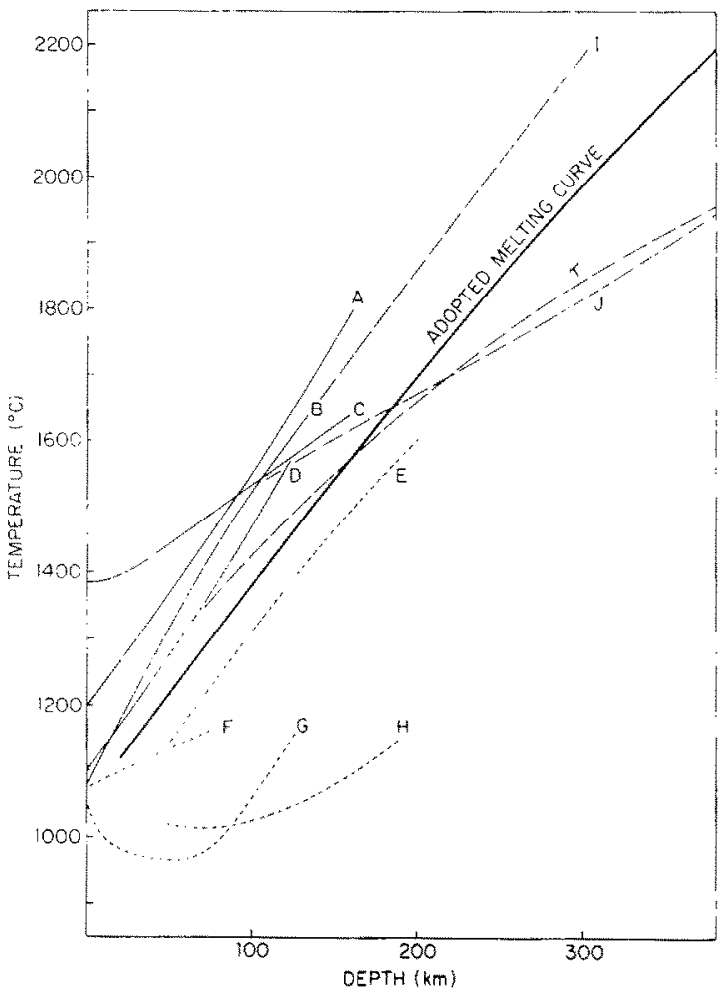

Fig. 5. Mantle melting curves. Solid lines are experimental solidus curves for dry peridotite and pyrolite: $A$ (Kushiro et al., 1968); $B$ (Ringwood, 1969); $C$ (Nishikawa et al., 1970 ); $D$ (Ito and Kennedy, 1967). Dashed lines are experimental solidus curves for wet peridotites and pyrolite: $E$ and $H$ (Kushiro et al., 1968); $F$ and $G$ (Green, 1973). Broken lines are estimates of melting curves: $I$ (Birch, 1969); $J$ (Uffen, 1952); $K$ (Griggs, 1972). Melting curve adopted for calculations is also shown.

wet and excess water conditions, respectively. A similar alteration of solidus position with water content is shown for pyrolite by curves $F(0.2 \%$ water $)$ and $G(6 \%$ water $)$. At pressures beyond the experimental range ( $50 \mathrm{kbar}$ or $160 \mathrm{~km}$ ) there is an even wider variety of suggestions for the melting curve. The suggestions include: curve $I$ used by Birch (1969) which is a straight ex trapolation of the Ringwood dry pyrolite solidus $B$; curve $J$ derived by Uffen (1952) from solid-state theory, and curve $K$ used by Griggs (1972) which coincides with $D$ at low pressures but is adjusted by a Simon fit to a melting temperature of $4000 \mathrm{~K}$ at the core-mantle boundary. The most striking feature of the experimental curves in Fig. 5 is the sensitivity of the position of the solidus to water content.

We adopt as the basis for later discussion the melting curve which is shown in Fig. 5. The curve corresponds to a sligh tly wet peridotite at shallow depths, follows the general trend of both wet and dry peridotite melting 
curves to about $200 \mathrm{~km}$, and then bends to join the Uffen curve below 500 $\mathrm{km}$. The uncertainties in available experimental data and the lack of such data over an appreciable pressure range of interest contribute to an overall imprecision in the curve.

The existence of the shear-wave low-velocity zone in the mantle beneath oceanic and most continental region (with the possible exception of some shields) has been demonstrated by many surface-wave studies. It is also widely, although not universally, believed that the high velocity "lid" overlying the low-velocity channel corresponds to the lithospheric plate, and the low-velocity channel itself corresponds to the asthenosphere.

In the following discussion, we note that certain characteristics of our family of geotherms show a systematic relationship to regional variations in the depth to the low-velocity zone, or equivalently to the thickness of the overlying lid. In accordance with the wide usage already cited, we use the term lithosphere to signify the layer of variable thickness overlying the lowvelocity zone, and accordingly refer to the thickness of the lithosphere.

Recently Leeds et al. (1974) and Yoshii $(1973,1975)$ have presented analyses of phase and group velocities and other geophysical data that lead to a model of the oceanic lithosphere thickening with age after formation at a spreading ridge. Parker and Oldenburg (1973) have also presented an analytical model of a cooling lithosphere that thickens by lower-boundary accretion as the depth at which the solidus temperature is exceeded progressively deepens with time. Figure 4 displays the results obtained by Leeds et al., using phase-velocity data from the Pacific Ocean, and illustrates the progressive thickening of the lithosphere with increasing age and decreasing heat flow. Also shown in Fig. 4 are two lines passing through the array of points. These lines mark the depth at which the oceanic geotherms of Fig. 3 attain 0.85 and 0.90 of the mantle solidus temperature. It is apparent that the depths defined by this range of temperatures adequately delineate the base of the lithosphere in oceanic regions.

Systematic investigations on the continents, analogous to the Leeds et al. study of the Pacific Ocean, support the general trend of increasing lithospheric thickness with decreasing heat flow. Biswas and Knopoff (1974) report a collection of solutions (velocity structures) from phase-velocity inversion in the north-central shield and platform of the United States; these velocity structures are characterized by a weakly developed or absent lowvelocity channel. The single solutions of Brune and Dorman (1963) and Wickens (1971) for the Canadian shield are consistent with and would appear to be a member of the solution set of Biswas and Knopoff. The shield and platform region exhibits a mean heat flow in the $40-50 \mathrm{~mW} \mathrm{~m}^{-2}$ range, which upon reference to the continental geotherms of Fig. 3 is seen to be exactly the range of heat flow that embraces a weak to absent low-velocity channel on the basis of the $0.85 T_{\mathrm{m}}$ intersection criterion. Data from Australia lend additional strength to this correlation. Goncz (1974) reports that a well defined low-velocity zone present in eastern Australia disappears 
beneath the western Australian shield, where the mean heat flow is less than $40 \mathrm{~mW} \mathrm{~m}{ }^{-2}$. In a region of high heat flow such as the Cordilleran thermalanomaly zone of western North America (which includes the Basin and Range province with a mean heat flow of about $90 \mathrm{~mW} \mathrm{~m}^{-2}$ ), the phasevelocity inversions indicate a well developed channel beginning at about 40 $50 \mathrm{~km}$ depth. The $90 \mathrm{~mW} \mathrm{~m}^{-2}$ geotherm of Fig. 3 intersects $0.85 T_{\mathrm{m}}$ at 44 $\mathrm{km}$. Thus it appears that the relationship of the geotherm families of Fig. 3 to the mantle solidus provides a framework, consistent in both continental and oceanic areas, which enables a direct link to be made between surface heat flow and depth to the base of the lithosphere.

Thus we are able to take the global map of heat flow (Fig. 1), utilize it as input to the operation of geotherm production (Fig. 3), and map the depth at which the resulting geotherms reach $0.85 T_{\mathrm{m}}$, thus producing a global map of the thickness of the lithosphere. Figure 6 displays the variation of lithospheric thickness, so derived, over the entire earth. The similarity to the heat-flow map in contour configuration is not surprising, for it is principally the heat flow that determines the steepness of the geotherms and the depth to $0.85 T_{\mathrm{m}}$. The lithosphere is thinnest over the oceanic ridges and thickest in the continental shields, with a range of about $300 \mathrm{~km}$; as previously noted, the shield geotherms do not reach $0.85 T_{\mathrm{m}}$ at any depth, and thus in a strict sense the asthenosphere should not exist beneath shiclds. More realistically, however, we expect that the lithosphere comprising shields does decouple from the deeper interior, probably at the depth at which the geotherm makes its closest approach to the solidus, at a fraction of $T_{\mathrm{m}}$ less than 0.85 . At this depth the viscosity will be greater than in a $0.85 T_{\mathrm{m}}$ astheno-

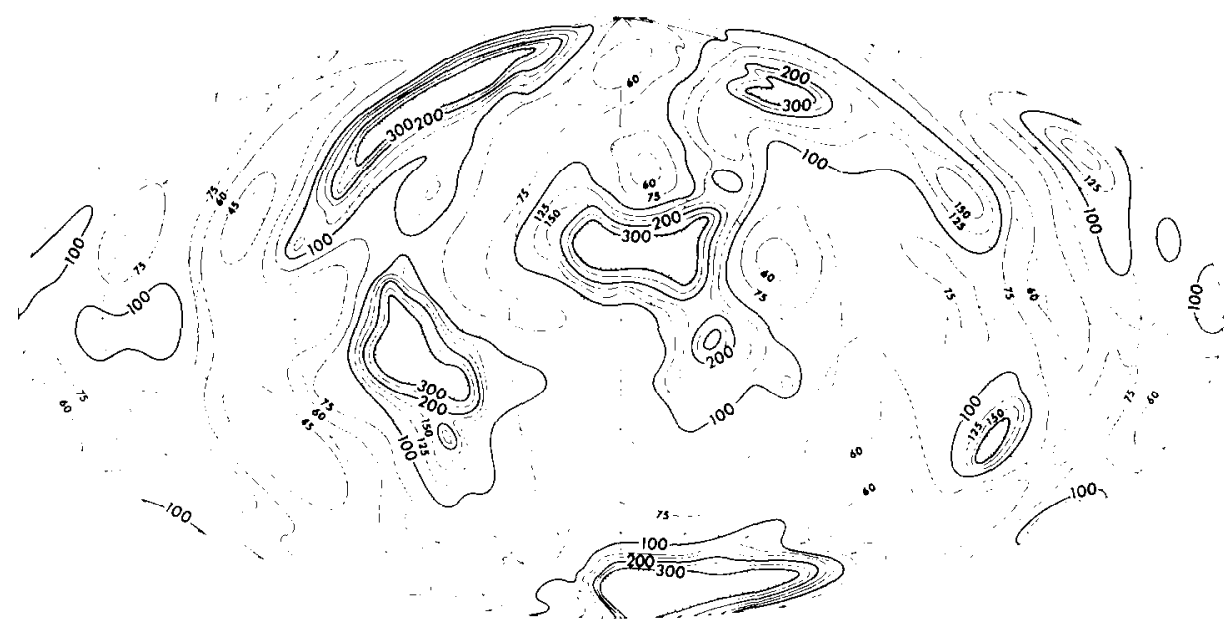

Fig. 6. Thickness of the lithosphere in kilometers determined from degree-12 spherical harmonic representation of global heat flow, and continental and oceanic geotherm families. Contour interval variable. 
sphere, leading to greater resistance to decoupling under shields than elsewhere.

We now address briefly the relationship of the thermal regime of the upper mantle to its rheological characteristics. Weertman (1970) has provided a summary of the rheology of mantle material to be expected on theoretical grounds and by analogy with experimental results obtained from metals and metal oxides. Of the several processes considered as possible creep mechanisms in the mantle, Nabarro-Herring diffusion creep, dislocation glide and dislocation climb are thought to be most important. The strain rate $\dot{\epsilon}$ for each of these mechanisms is given by Weertman in the following forms:

$\dot{\epsilon}=F(\sigma) \exp [-(E+p V) / k T]=F(\sigma) \exp \left(-A T_{\mathrm{m}} / T\right)$

where $F(\sigma)$ is a generally non-linear function primarily dependent on stress but may contain other variables as well, $E$ and $V$ are the activation energy and volume for diffusion, $k$ is Boltzmann's constant, $A$ is a material constant, $T_{\mathrm{m}}$ is the (absolute) melting temperature, and $T$ and $p$ are the ambient temperature and pressure. An effective viscosity can be defined as the ratio $\sigma / \dot{\epsilon}$. It is apparent from the second form of $\dot{\epsilon}$ in eq. 2 that for a given stress level, variations in $T / T_{\mathrm{m}}$ correspond directly to variations in viscosity.

However, it is interesting to note (see Figs. 4 and 6) that over much of the globe, a single value of $T / T_{\mathrm{m}}$ maps the base of the lithosphere, suggesting that decoupling of the lithosphere occurs at a depth where the viscosity falls below a certain value. Thus it is possible to view Fig. 6 as the depth at which a decoupling viscosity is reached. The exception to this generality is to be found beneath shields, where the geotherms do not reach the critical value of $0.85 T_{\mathrm{m}}$ at any depth. Thus the viscosity beneath shields, other things being equal, should be greater than elsewhere. Our calculations, using uniform stress, the material constants of Weertman, and $0.75 T_{\mathrm{m}}$ as the closest approach of the geotherm to the solidus beneath shields, yield a minimum viscosity an order of magnitude greater than that corresponding to $0.85 T_{\mathrm{m}}$.

What are the implications of this regional variation of lithospheric thickness and viscosity for plate motions? We believe that the principal force retarding plate motions is the drag force acting at the bottom surface of the plate due to the viscous coupling between the lithosphere and underlying asthenosphere. The regions where the viscous drag will be particularly concentrated can be seen in Fig. 6 and center on the major shield areas of the continents. Such a proposal is not new: in an earlier paper (Chapman and Pollack, 1974) we proposed a "viscous anchor" beneath the West African shield, and Knopoff (1972), Alexander and Sherburne (1972) and Alexander (1974) have described a deep structure for several shields that qualitatively supports such an idea. However, more substantial support for the concept comes from recent studies on driving forces and the motions of plates. Minster et al. (1974) constructed a global kinematic model of instantaneous plate motions and showed that in a hotspot frame of reference, completely 
oceanic plates are moving about five times faster than plates containing continents. This effect may be attributed to enhanced drag beneath continents, and/or to some other factor such as the presence of subducted slabs, which are thought to accelerate the oceanic plates to which they are attached. Further progress on this problems was made by Solomon and Sleep (1974) who calculated the absolute velocity field under a series of assumptions about the driving and retarding mechanisms, including drag concentration beneath continents. Although they found their absolute velocities were rather insensitive to different models of driving forces, they report a bestfitting model in which the drag coefficient beneath continents is three to four times that beneath oceans.

A similar but more comprehensive result comes from a recent study by Forsyth and Uyeda (1974) on the relative importance of driving mechanisms. They considered eight possible forces and then solved the inverse problem of determining the relative strength of the forces from the observed relative motions and geometries of the lithospheric plates. Their results indicate that the forces on the downgoing slab control the velocity of the oceanic plates and are considerably greater than other forces. Significantly, however, continental drag is the primary regulator of the velocity of plates not attached to downgoing slabs, and drag under continents appears to be approximately eight times stronger than drag under oceanic portions of the plate.

It should be noted that in the above-mentioned studies the plates are simply classified as predominantly continental or predominantly oceanic, or else individual plates are subdivided into continental and ocean regions. Our map of lithospheric thickness (Fig. 6) shows no special transitions at continentocean boundaries; rather, the sharp gradients generally occur within the continents themselves. We anticipate that further driving-force studies will be able to test the validity of the strong intra-continental variation in mantle drag implicit in Fig. 6.

The secular variation in heat flow and lithospheric thickness from younger to older tectonic provinces has other interesting implications. In the past, lithospheric plates now comprising shields were certainly thinner and the asthenosphere was better developed, conditions that would have facilitated Paleozoic and Precambrian continental drift. In the future, as shields continue to wicken and develop substantial viscous anchors we may expect plate motion to diminish and eventually to cease. We also note that, as the thicknesc of a plate affects its flexural rigidity and buckling characteristics, it may be an important parameter governing the tectonic style of deformation. A thinner lithosphere may become more involved in folding and/or tensional disruption than would a thicker lithosphere. It is conceivable that the greenstone belts and surrounding granitic terrain that seem so ubiquitously distributed in the ancient cratonic elements of several continents may be the characteristic tectonic style and petrologic assemblage to develop in a $40 \mathrm{~km}$ high heat flow continental lithosphere interacting with an extremely 
mobile asthenosphere (Green, 1975; McKenzie and Weiss, 1975). As more geophysical and petrological data become available, permitting the calculation of lithospheric thickness versus time for several different regions, we suggest that such correlations of tectonic style will emerge.

\section{ACKNOWLEDGMENT}

This research was supported in part by the U. S. National Science Foundation, Earth Science Section, under Grants GA-36360 and DES75-17065.

\section{REFERENCES}

Alexander, S.S., 1974. Comparison of crust and mantle structure beneath shields and the influence of shield on the dynamics of plate motions. EOS Trans. Am. Geophys. Union, 55: 358-359 (abstract).

Alexander, S.S. and Sherburne, R.W., 1972. Crust and mantle structure of shields and their role in global tectonics. EOS Trans. Am. Geophys. Union, 53: 1043 (abstract).

Birch, F., 1969. Density and composition of the upper mantle: first approximation as an olivine layer. In: P.J. Hart (editor), The Earth's Crust and Upper Mantle. Geophys. Monogr. 13, American Geophysical Union, Washington, D.C., pp. 18-36.

Birch, F., Roy, R.F. and Decker, E.R., 1968. Heat flow and thermal history in New York and New England. In: E. Zen, W.S. White, J.B. Hadley and J.B. Thompson, Jr. (editors), Studies of Appalachian Geology: Northern and Maritime. Interscience, New York, pp. 437-451.

Biswas, N.N. and Knopoff, L., 1974. The structure of the upper mantle under the United States from the dispersion of Rayleigh waves. Geophys. J. R. Astron. Soc., 36: 515-539 .

Boyd, F.R., 1973. A pyroxene geotherm. Geochim. Cosmochim. Acta, 37: 2533-2546.

Brune, J. and Dorman, J., 1963. Seismic waves and earth structure in the Canadian shield. Bull. Seismol. Soc. Am., $53: 167-210$.

Chapman, D.S. and Pollack, H.N., 1974. Cold spot in West Africa: anchoring the African plate. Nature, 250:477-478.

Chapman, D.S. and Pollack, H.N., 1975a. Heat flow and incipient rifting in Central Africa. Nature, 256:5512:28-30.

Chapman, D.S. and Pollack, H.N., 1975b. Global heat flow: a new look. Earth Planet. Sci. Lett., 28: 23-32.

Clark, S.P. and Ringwood, A.E., 1964. Density distribution and constitution of the mantle. Rev. Geophys. Space Phys, $2: 35-88$.

Davis, E.E. and Lister, C.R.B., 1974. Fundamentals of ridge crest topography. Earth Planet. Sci. Lett., $21: 405-413$.

Forsyth, D. and Uyeda, S., 1974. The driving mechanisms of plate tectonics. EOS Trans. Am. Geophys. Union, 56:1186 (abstract).

Goncz, J.H., 1974. Upper mantle shear wave velocity differences beneath Australia by surface wave analysis and inversion, 10 to 200 second period range. EOS Trans. Am. Geophys. Union, $56: 1144$ (abstract).

Green, D.H., 1973. Contrasted melting relations in a pyrolite upper mantle under midoceanic ridge, stable crust and island arc environments. Tectonophysics, $17: 285-$ 297.

Green, D.H., 1975. Genesis of Archean peridotitic magmas and constraints on Archean geothermal gradients and tectonics. Geology, 3: 15-18.

Griggs, D.T., 1972. The sinking liihosphere and the focal mechanisms of deep earth- 
quakes. In: E.C. Robertson (editor), The Nature of the Solid Earth, McGraw-Hill, New York, pp. 361-384.

Hyndman, R.D., Lambert, I.B., Heier, K.S., Jaeger, J.C. and Ringwood, A.E., 1968. Heat flow and surface radioactivity measurements in the Precambrian shield of Western Australia. Phys. Earth Planet. Inter., 1: 129-135.

Ito, K. and Kennedy, G.C., 1967. Melting and phase relations in a natural peridotite to 40 kilobars. Am. J. Sci., 265: 519-538.

Jaeger, J.C., 1970. Heat flow and radioactivity in Australia. Earth Planet. Sci. Lett., 8: $285-292$.

Kennedy, G.C., 1959. The origin of continents, mountain ranges, and ocean basins. Am. Sci., $47: 491-504$.

Knopoff, L., 1972. Observation and inversion of surface-wave dispersion. Tectonophysics, $13: 497-519$.

Kushiro, I., Syono, Y. and Akimoto, S., 1968. Melting of a peridotite nodule at high pressures and high water pressures. J. Geophys. Res., 73: 6023-6029.

Lachenbruch, A.H., 1970. Crustal temperature and heat production: implications of the linear heat-flow relation. J. Geophys. Res., 75: 3291-3300.

Leeds, A.R., Knopoff, L. and Kausel, E.G., 1974. Variations of upper-mantle structure under the Pacific Ocean. Science, 186: 141-143.

McKenzie, D.P., 1967. Some remarks on heat flow and gravity anomalies. J. Geophys. Res., 72:6261-6273.

McKenzie, D.P. and Weiss, N., 1975. Speculations on the thermal and tectonic history of the earth. Geophys. J. R. Astron. Soc., 42:131-174.

Minster, J.B., Jordan, T.H., Molnar, P. and Haines, E., 1974. Numerical modelling of instantaneous plate tectonics. Geophys. J. R. Astron. Soc., 36:541- 576.

Nishikawa, M., Kono, S. and Aramaki, S., 1970. Melting of lherzolite from Ichinomegata at high pressures. Phys. Earth Planet. Inter., 4: 138-144.

Parker, R.L. and Oldenburg, D.W., 1973. Thermal model of ocean ridges. Nature Phys. Sci., 242: 137-139.

Polyak, B.G. and Smirnov, Ya.B., 1968. Relationship between terrestrial heat flow and the tectonics of continents. Geotectonics, 4: 205-213.

Rao, R.V.M. and Jessop, A.M., 1975. A comparison of the thermal characters of shields. Can. J. Earth Sci., 12:347-360.

Ringwood, A.E., 1969. Composition and evolution of the upper mantle. In: P.J. Hart (editor), 'The Earth's Crust and Upper Mantle. Geophys. Monogr. 13, American Geophysical Union, Washington, D.C., pp. 1-17.

Roy, R.F., Blackwell, D.D. and Birch, F., 1968. Heat generation of plutonic rocks and continental heat-flow provinces. Earth Planet. Sci. Lett., 5: 1-12.

Sass, J.H. and Munroe, R.J., 1974. Basic heat flow data from the United States. Open File Rep. 74-79, U. S. Geological Survey, Menlo Park, Calif.

Sass, J.H., Lachenbruch, A.H., Munroe, R.J., Greene, G.W. and Moses, Jr., T.H., 1971 Heat flow in the western United States. J. Geophys. Res., 65: 6376-6413.

Schatz, J.F. and Simmons, G., 1972. Thermal conductivity of earth materials at high temperatures. J. Geophys. Res., 77: 6966-6983.

Sclater, J.G. and Francheteau, J., 1970. The implication of terrestrial heat flow observations on current tectonic and geochemical models of the crust and upper mantle of the earth. Geophys. J. R. Astron. Soc., 20:509-542.

Sclater, J.G., Lawver, L.A. and Parsons, B., 1975. Comparison of long-wavelength residual elevation and free-air gravity anomalies in the north Atlantic and possible implications for the thickness of the lithospheric plate. J. Geophys. Res., 80: 1031-1052.

Smithson, S.B. and Decker, E.R., 1974. A continental crustal model and its geothermal implications. Earth Planet. Sci. Lett., 22: 215-225.

Solomon, S.C. and Sleep, N.H., 1974. Some simple physical models for absolute plate motions. J. Geophys. Res., $79: 2557-2567$. 
Uffen, R.J., 1952. A method of estimating the melting-point gradient in the earth's mantle. Trans. Am. Geophys. Union, 33:893-896.

Weertman, J., 1970. The creep strength of the earth's mantle. Rev. Geophys. Space Phys., 8: 145-168.

Wickens, A.J., 1971. Variations in lithospheric thickness in Canada. Can. J. Earth Sci., 8: 1154-1162.

Yoshii, R., 1973. Upper-mantle structure beneath the north Pacific and the marginal seas. J. Phys. Earth, 21: 313.

Yoshii, R., 1975. Regionality of group velocities of Rayleigh waves in the Pacific and thickening of the plate. Earth Planet. Sci. Lett., 25: 305-312. 